A Regional Seismic Array of Three-Component Stations in Central Saudi Arabia

A. Al-Amri, D. Harris, M. Fnais, A. Rodgers, M. Hemaida

May 4, 2011

Seismological Research Letters 
This document was prepared as an account of work sponsored by an agency of the United States government. Neither the United States government nor Lawrence Livermore National Security, LLC, nor any of their employees makes any warranty, expressed or implied, or assumes any legal liability or responsibility for the accuracy, completeness, or usefulness of any information, apparatus, product, or process disclosed, or represents that its use would not infringe privately owned rights. Reference herein to any specific commercial product, process, or service by trade name, trademark, manufacturer, or otherwise does not necessarily constitute or imply its endorsement, recommendation, or favoring by the United States government or Lawrence Livermore National Security, LLC. The views and opinions of authors expressed herein do not necessarily state or reflect those of the United States government or Lawrence Livermore National Security, LLC, and shall not be used for advertising or product endorsement purposes. 


\title{
A Regional Seismic Array of Three-Component Stations in Central Saudi Arabia
}

\author{
Abdullah Al-Amri ${ }^{1}$, David Harris ${ }^{2,3}$, Mohammed Fnais ${ }^{1}$, Arthur Rodgers ${ }^{3}$, and Moustafa \\ Hemaida $^{4}$ \\ ${ }^{1}$ Department of Geology, King Saud University, Riyadh, Saudi A rabia \\ ${ }^{2}$ Deschutes Signal Processing LLC, Maupin, OR, United States of A merica \\ ${ }^{3}$ A tmospheric, Earth and Energy Department, Lawrence Livermore National Laboratory, \\ Livermore, CA, 94551 United States of America \\ ${ }^{4}$ Research Institute of Petroleum and Gas, King Abdulaziz City for Science and Technology, \\ Riyadh, Saudi A rabia \\ Manuscript submitted to Seismological Research Letters \\ May 6, 2011
}

\section{Introduction}

Seismic arrays are used to enhance signals and suppress noise as well as to estimate the slowness and azimuth of signals. Seismic monitoring traditionally has relied upon seismic arrays to reduce detection (magnitude) thresholds by increasing signal-to-noise ratios (SNR) and to contribute to event formation by improving phase identification and association. A seismic array differs from a local network of seismic stations mainly by the techniques used for data analysis. In principle, a network of seismic stations can be used as an array, and data from an array can be analyzed as from a network. However, most array processing techniques require high signal coherency across the array, and this puts important constraints on the array geometry, spatial extent, and data quality. Furthermore, proper analysis of array data is dependent on a stable, high precision relative timing of all array elements. This is required because the measurement of 
(usually very small) time differences of the arrival of seismic signals between the different sensors plays an important role in all array processing techniques.

The Department of Geology of King Saud University has established a small-aperture $(\sim 3.5$ $\mathrm{km}$ ) three-component seismic array in central Saudi Arabia at a hard rock site on the Arabian Shield (Figure 1a). The facility consists of well-constructed vaults in hard rock outcrops in a region that has very low background noise. The deployed equipment consists of a broadband three-component sensor (STS-2) at the center element and eight short-period three-component sensors at the outlying elements (Figure 1b). The objectives of this deployment are to improve constraints on the structure and physical state of the lithosphere beneath the Arabian Shield and the Red Sea, to provide information concerning the tectonic evolution of the Arabian Plate, to enhance existing models of the crust, and to provide additional constraints on seismicity in the region, especially at lower magnitudes, which we expect to lead to more complete and accurate earthquake catalogs. We anticipate improving velocity models of the crust which we intend to use in investigations of attenuation, ultimately contributing to assessments of seismic hazard in the region. Better models of upper mantle structure may provide insights into the depth of the source of volcanism (the Harrats, Figure 1a) in the region and uplift of the Arabian Shield.

Since this is the first array in the region designed for coherent regional signal processing and because so few seismic stations in the Middle East provide openly available broadband data, this array will provide unique and valuable data. This paper describes some preliminary analysis of the array data. We measured coherence of (regional and teleseismic) signals and noise as a function of inter-sensor separation and frequency. We also made slowness and azimuth 
measurements of regional and teleseismic phases and compared these to predictions from radial earth models to characterize path-specific propagation. We characterized background noise at the sites. Because few fully three-component arrays exist, data from the KSU array is anticipated to contribute to the general understanding of processing strategies that combine beamforming with polarization analysis. We will also be interested to investigate the seasonal and diurnal noise spectral levels, and frequency-dependent spatial structure (coherence and azimuthal dependence).

\section{Geologic and Seismotectonic Setting}

The accretionary evolution of the Arabian plate is thought to have originated and formed by amalgation of five Precambrian terranes. These are the Asir, Hijaz, and Midyan terranes from the western part of the Arabian shield, and from the eastern side of the shield are the Afif terrane and the Amar arc of the Ar Rayn micro-plate. The western fusion is along the Bir Umq and Yanbu sutures (Loosveld et al 1996). The eastern accretion may have started by about 680-640 million years ago (Ma) when the Afif terrane collided with the western shield along the Nabitah suture. At about $670 \mathrm{Ma}$, a subduction complex formed west of Amar arc. Along this subduction zone, the Afif terrane and Ar Rayn microplate collided around 640-620 Ma. (Al-Husseini 2000). The north trending Rayn anticlines and conjugate northwest and northeast fractures and faults may have formed at this time.

The Arabian Shield is an ancient land mass with a trapezoidal shape and area of about 770,000 sq. km. Its slightly-arched surface is a peneplain sloping very gently toward the north, northeast, and east. The framework of the shield is composed of Precambrian rocks and metamorphosed 
sedimentary rocks intruded by granites. The fold-fault pattern of the shield, together with some stratigraphic relationships suggests that the shield has undergone two orogenic cycles. To the first order, the Arabian shield is composed of two layers, each about $20 \mathrm{~km}$ thick, with average velocities of about $6.3 \mathrm{~km} / \mathrm{s}$ and $7 \mathrm{~km} / \mathrm{s}$ respectively (Mooney et al 1985). The crust thins rapidly to less than $20 \mathrm{~km}$ total thickness at the western shield margin, beyond which the sediments of the Red Sea shelf and coastal plain are underlain by oceanic crust.

The platform consists of the Paleozoic and Mesozoic sedimentary rocks that unconformably overlie the shield and dip very gently and uniformly to the E-NE towards the Arabian Gulf (Powers et al., 1966). The accumulated sediments in the Arabian platform represent the southeastern part of the vast Middle East basin that extend eastward into Iran, westward into the eastern Mediterranean and northward into Jordan, Iraq and Syria.

The Arabian shield isolated the Arabian platform from the north African Tethys and played an active paleogeographic role through gentle subsidence of its northern and eastern sectors during the Phanerozoic, allowing almost $5000 \mathrm{~m}$ of continental and marine sediments to be deposited over the platform. This accumulation of sediments represents several cycles from the Cambrian onward, and now forms a homocline dipping very gently away from the Arabian shield.

Several structural provinces can be identified within the Arabian platform: 1) an interior homocline in the form of a belt, about $400 \mathrm{~km}$ wide, in which the sedimentary rocks dip very gently away from the shield outcrops, 2) an interior platform, up to $400 \mathrm{~km}$ wide, within which the sedimentary rocks continue to dip regionally away from the shield at low angles, and 3) intrashelf depressions, found mainly around the interior homocline and interior platform . 
The Saudi Arabian Broadband Deployment (Vernon and Berger, 1997; Al-Amri et al., 1999) provided the first broadband recordings for the Arabian Shield and Platform. This deployment consisted of 9 broadband, three-component seismic stations along a transect similar to a seismic refraction study (Mooney et al., 1985; Gettings et al., 1986; Badri, 1991). Data from this deployment resulted in several reports of crustal and upper mantle structure (Sandvol et al., 1998; Mellors et al., 1999; Rodgers et al., 1999; Benoit et al., 2003; Mokhtar et al., 1997). The crustal model of the western Arabian Platform shows a slightly higher P-velocity for the upper crust in the Arabian Shield than in the Platform. Also the crust of the Platform appears to be 3-5 $\mathrm{km}$ thicker than in the Shield. The Moho discontinuity beneath the western Arabian Platform occurs at a depth of $40-45 \mathrm{~km}$, and the velocity of the upper mantle is about $8.2 \mathrm{~km} / \mathrm{sec}$ (Al-Amri 1998; 1999; Rodgers et al., 1999; Tkalcic et al., 2006).

Generally, the crustal thickness in the Arabian Shield varies from about $15 \mathrm{~km}$ in the Red Sea, to $20 \mathrm{~km}$ along the Red Sea coast to about $35-40 \mathrm{~km}$ in the central Arabian Shield (Sandvol et al., 1998; Al-Damegh et al., 2005; Tkalcic et al., 2006). Large-scale seismic tomography (e.g. Debayle et al., 2001) suggest that a low-velocity anomaly in the upper mantle extends laterally beneath the Arabian Shield from the Red Sea in the west to the Shield-Platform boundary in the east. Additionally, Debayle et al. (2001) observed a narrow region of low velocity beneath the Red Sea and the western edge of the Arabian Shield, extending to $650 \mathrm{~km}$ depth. Recent tomographic imaging by Park et al. (2007) using SANDSN data found low velocities extending to $400 \mathrm{~km}$ in the upper mantle beneath the southern Red Sea and Arabian Shield, but more 
normal velocities beneath the northern Red Sea, suggesting different geodynamic connections between rifting of the Red Sea and mantle upwelling in the southern and northern Red Sea.

High-frequency regional S-wave phases are quite different for paths sampling the Arabian Shield than those sampling the Arabian Platform (Mellors et al., 1999; Al-Damegh et al., 2004; Pasyanos et al., 2009). In particular the mantle Sn phase is nearly absent for paths crossing parts of the Arabian Shield, while the crustal Lg phase has abnormally large amplitude. This may result from an elastic propagation effect or extremely high mantle attenuation and low crustal attenuation occurring simultaneously, or a combination of both. High-frequency Lg does not propagate as efficiently across the Arabian Platform compared to the Shield but Sn does propagate efficiently. This observation suggests that crustal attenuation is low in the higher velocity crust of the Arabian Shield, or that sedimentary structure in the Arabian Platform attenuates and disrupts the crustal waveguide for Lg. These observations imply that highfrequency ground motions will propagate with lower attenuation in the Arabian Shield than in the Arabian Platform.

\section{Installation and Preliminary Noise Results}

Great care was taken to site the stations of the Ar Rayn array on Precambrian outcrops. Figure 2 shows a representative station site (AR25). Note that the station is sited adjacent to an outcrop where it was possible to excavate a vault into contact with undisturbed Precambrian bedrock. The inside dimensions of the vault are 1.6 meters square and 2 meters deep (Figure 3). At the bottom a 1.4 meter by 1.4 meter concrete pier, 20 centimeters thick, was poured directly on 
bedrock. This dimension affords a $10 \mathrm{~cm}$ separation between the pier and the walls of the vault for noise isolation. The walls themselves are composed of two shells, a concrete block wall on the outside, with foam filling the voids of the blocks for thermal isolation, and a $20 \mathrm{~cm}$ inside wall poured of solid concrete. Neither of the walls contains any steel reinforcement to prevent possible noise contributed to the motion of the mass. The top of the vault is covered by a double door with $10 \mathrm{~cm}$ of foam for thermal isolation. The walls and top of the vaults are flush with the ground surface to minimize wind noise. The 80 watt solar panel is mounted close to the ground surface also to minimize wind noise that would be transmitted into the vault had a mast mounting been used.

The short-period instruments are Kinemetrics SS-1 Ranger seismometers (1 Hz free period). Three are arranged in a three-component configuration as shown in Figure 3. The data are acquired by Quanterra Q330 data loggers and stored on Bailer 44 data storage devices with thirty-two gigabytes of flash memory. The sampling rate is 100 samples per second for each channel. The single broadband sensor at the center of the array (AR00) is a Streckheisen STS-2. Otherwise the configuration of this installation is the same as the short-period stations.

Figure 4 shows noise level as a function of frequency for the three components of the broadband center element of the array, and follows the format of Astiz (1997). The vertical axis is acceleration power expressed in decibels with respect to $1 \mathrm{~m}^{2} / \mathrm{s}^{4} / \mathrm{Hz}$. The grey lines denote the USGS low and high noise models of Peterson (1993). The methodology of this noise estimate differs from that used to determine the USGS low- and high-noise models and consequently absolute power levels may differ slightly due to bias induced by different tapers and windows. 
At mid- and higher frequencies, the three noise spectra lie near the USGS low noise model departing somewhat above about $2 \mathrm{~Hz}$. The high frequency noise, especially the distinct spectral lines, could be instrument noise or cultural noise from the nearby town of Ar Rayn, which is 15 kilometers from the array.

In general, noise levels are similar for all channels for frequencies greater than $1 \mathrm{~Hz}$. Between $1 \mathrm{~Hz}$ and roughly $0.1 \mathrm{~Hz}$, the vertical is slightly noisier than the horizontals. At frequencies less than $0.1 \mathrm{~Hz}$, the horizontal components are much noisier, creating an obvious discrepancy with the low-noise-model. The long-period noise levels on the horizontal channels may present a problem for surface wave studies and regional moment tensor inversions, which are forced to depend solely on vertical data for moderate sized events. The source of the noise is not clear. One possibility is that the long period noise may be due to small tilts which affect the horizontal more than the verticals because horizontal tilts greatly increase the effect of the local gravity vector. Tilt effects can be quite large compared to the signals normally recorded, and may be due to prevailing winds and/or transient thermal effects caused by large diurnal temperature variations in the desert.

The body-wave magnitude $(\mathrm{mb})$ detection threshold for the distance range of 10-100 degrees is about $\mathrm{m}_{\mathrm{b}}>3.5$ (Vernon and Berger, 1997). Minimum detectable magnitudes are estimated for RAYN station using the observed noise levels over $1 \mathrm{~Hz}$. The $\mathrm{m}_{\mathrm{b}}$ detection threshold for the distance range of 5-10 degrees is about 2.7-3.0 assuming the signal-to-noise ratio of $3 \mathrm{~dB}$ or better (Al-Amri et al., 1999). They indicated that seasonal noise levels varied at RAYN, with April to June being the quietest and with October to December being the nosiest months. Slight 
changes in peak microseism frequency also occurred seasonally. Absolute noise levels near the microseism frequency $(0.1$ to $0.2 \mathrm{~Hz})$ were about equal for all seasons at $-140 \mathrm{~dB}$. Above $1 \mathrm{~Hz}$, RAYN station shows an increase in seasonal variations from $-140 \mathrm{~dB}$ in the summer to $-160 \mathrm{~dB}$ in the winter. Mellors (1998) showed that noise levels at nine broadband stations (STS-2) across the Arabian Shield are similar for all channels for a given station for frequencies greater than 0.9 Hz. Between $0.9 \mathrm{~Hz}$ and roughly $0.1 \mathrm{~Hz}$, the vertical is slightly noisier than the horizontals, and at frequencies less than $0.1 \mathrm{~Hz}$, the horizontals are much noisier.

\section{Preliminary Data Processing}

We show three signal processing examples using Ar Rayn array data. The first is a check of coherence using a teleseismic observation of $a n \mathrm{~m}_{\mathrm{b}} 5.3$ earthquake in the vicinity of Greece (USGS preliminary hypocenter $38.425 \mathrm{~N}$ and $44.022 \mathrm{E}$, depth $10 \mathrm{~km}$ ) that occurred on January 22, 2010 at 00:46:57.5 GMT. Figure 5 (left) displays the vertical waveforms of seven of the array short-period elements in a 30-second window about the initial P phase filtered 1-3 Hz. Figure 5 (right) shows an FK spectrum computed from that P phase. The back-azimuth (-63.4 degrees) and phase velocity (10.2) values estimated from the spectral peak were used to align the signals for a coherence analysis. That analysis is shown in Figure 6, with the aligned $\mathrm{P}$ waveforms on the top and, on the bottom, the correlation values of all 21 distinct pairs of signals plotted as a function of sensor separation. The correlation values are quite high, as is expected for a low-frequency $(\sim 1 \mathrm{~Hz})$ teleseismic $\mathrm{P}$ phase observed across a 3 kilometer aperture. Nonetheless, the high correlation values indicate desirable uniformity of vault installation, coupling to bedrock, site response and instrumentation. 
An interesting observation of a local event is shown in Figures 7 through 9. This is a local magnitude 2.3 (KACST catalog) event which occurred approximately 260 kilometers NNE of the array. Only the Lg phase is clear in the data (Figure 7) filtered into the 0.8 to $3 \mathrm{~Hz}$ band. There is a hint of a $\mathrm{P}$ phase approximately 30 seconds before the Lg signal, but no distinct arrival can be reliably picked. Higher frequency filter bands do not improve the signal to noise ratio in this case. A wideband (1-3 Hz) FK spectrum of the Lg arrival (Figure 8) provides a usable backazimuth and a phase velocity $(3.79 \mathrm{~km} / \mathrm{s})$ confirming the identity of the $\mathrm{Lg}$ phase. The measured Lg back-azimuth and an assumed phase velocity of $8 \mathrm{~km} / \mathrm{sec}$ can be used to search for the $\mathrm{P}$ phase arrival. Figure 9 shows an individual vertical waveform (top trace) and the P beam (middle trace). The (probable) Pn phase now is clearly visible. Still greater processing gain can be obtained for the $\mathrm{P}$ phase by combining beamforming and polarization filtering. The third trace in the figure shows a polarized beam obtained by forming separate beams on the vertical, north and east components of the array, then rotating the resulting three-component beam set onto the polarization vector of Pn for this event (back-azimuth 29.5 degrees, angle of incidence 39 degrees). The angle of incidence used assumes a near-surface medium P-wave velocity of 5 $\mathrm{km} / \mathrm{s}$. This processing approach roughly doubles the signal-to-noise ratio of the incident $\mathrm{P}$ wave relative to the vertical beam enhancing our ability to pick and identify this phase.

The three-component beam may be summarized mathematically by:

$$
b(t)=\frac{1}{N} \mathbf{c} \cdot \sum_{i=1}^{N} \mathbf{r}_{i}\left(t-\Delta_{i}\right)
$$


where bold quantities are vectors. The vector of three-component signals recorded at station $i$ is denoted by:

$$
\mathbf{r}_{i}(t)=\left[\begin{array}{l}
z_{i}(t) \\
n_{i}(t) \\
e_{i}(t)
\end{array}\right]
$$

where the triple $\left\{z_{i}(t), n_{i}(t), e_{i}(t)\right\}$ represents the vertical, north and east components of the station. $N$ is the number of stations in the array, and the propagation delays $\left\{\Delta_{i}\right\}$ are described by a plane wave model:

$$
\Delta_{i}=\mathbf{s} \cdot \mathbf{x}_{i}
$$

The vector $\mathbf{s}$ is the horizontal slowness vector, $s$ is scalar horizontal slowness (ray parameter), and $\mathbf{c}$ is the polarization vector for $\mathrm{P}$ waves:

$$
\mathbf{s}=s\left[\begin{array}{c}
\cos \theta \\
\sin \theta
\end{array}\right] \quad \mathbf{c}=\left[\begin{array}{c}
\cos \varphi \\
\sin \varphi \cos \theta \\
\sin \varphi \sin \theta
\end{array}\right]
$$

where $\theta$ is the azimuth of propagation of north through east and $\varphi$ is the angle of incidence with the vertical axis. Finally, the vector $\mathbf{x}_{i}$ represents the horizontal offset of station $i$ from a common reference point.

Our final example of beamforming is an extraction of crustal and upper mantle $\mathrm{P}$ phases for an event in the Harrat Lunayyir volcanic center (25.215N 37.796E), approximately 790 kilometers from the array. The event occurred on April 15, 2010 (04:10:04.25 GMT) and was estimated to be a magnitude 3.7 event by the Saudi Geological Survey. Figure 10 shows single channel 
recordings and beams for this event. The top trace is a vertical channel (station AR11) filtered into the 1-4 Hz band. A pronounced Lg phase is apparent, preceded by approximately 110 seconds by a very weak P phase. The three bottom traces in the figure are detailed views around the $\mathrm{P}$ phases, with the first of the three being again the filtered single vertical trace. The second trace is the beam formed from the vertical components only, and the third trace is the threecomponent beam (equation 1). Note that, as with the smaller near-regional event, the threecomponent beam roughly doubles the power SNR for the Pn phase. Pg also is more clearly visible on this beam, arriving about 14 seconds after Pn.

\section{Summary}

Based on the background noise level observed at the center element of the Ar Rayn seismic array, coherence analysis and beamforming results for representative events in the region, this array should prove to be very valuable for examining seismicity and structure in the Arabian peninsula. Noise levels approach the Peterson low noise model (1993) between $0.05 \mathrm{~Hz}$ and 2 $\mathrm{Hz}$ and are low in the $2-10 \mathrm{~Hz}$ band. Noise levels are elevated on the horizontal elements below $0.05 \mathrm{~Hz}$, which may limit measurements of surface wave dispersion and moment tensor inversions, but should not affect high-frequency beamforming capabilities.

Initial beamforming results demonstrate that the array will provide improve estimates of $\mathrm{P}$ arrival times and waveforms for small events in the region. Since the array is one of only a few with three-component stations deployed at all elements, it should provide opportunities to examine more sophisticated combinations of beamforming and polarization filtering, and phase identification and association through three-component FK analysis. Initial results for two 
events, one at local distance and a second at regional distance confirm this expectation.

\section{Acknowledgments}

The authors would like to express their thanks and gratitude to the National Strategy Plan for Science, technology and innovation at KACST for funding this project (Grant no. 08ENV 516-2). We extend our sincerest thanks to Mr. Fahad Al-Omairah and Ahmad Rabea of King Saud University for supervising construction of the array stations. We thank Michael Pasyanos for comments on the manuscript. This work performed in part under the auspices of the U.S. Department of Energy by Lawrence Livermore National Laboratory under Contract DEAC52-07NA27344, LLNL contribution LLNL-JRNL-482791.

\section{References}

Al-Amri, A.M. (1998). The crustal structure of the western Arabian Platform from the spectral analysis of long-period P-wave amplitude ratios, Tectonophysics, 290, 271-283.

Al-Amri, A.M. (1999). The crustal and upper-mantle structure of the interior Arabian platform, Geophysical Journal International, 136,421-430.

Al-Amri, A. M., R. Mellors and F. Vernon (1999). Broadband seismic noise charateristics of the Arabian Shield, The A rabian Journal for Science and Engineering, 24, 2A, 99-113.

Al-Amri, A. M., Davis, P., Al-Amri, M., Gharib, A. and Berger, J. (1999). Seismic characteristics of RAYN/ GSN station, Saudi Arabia. J. of King Saud University: Science (2), V. 11, pp. $81-92$. 
Al-Damegh, K., E. Sandvol, and M. Barazangi (2005). Crustal structure of the Arabian Plate: new constraints from the analysis of teleseismic receiver functions, Earth Planet. Sci. Letts., 231, 177-196.

Al-Damegh, K., Sandvol, E., Al-Lazki, A. and Barazangi, M. (2004). Regional wave propagation (Sn and Lg) and Pn attenuation in the Arabian plate and surrounding regions, Geophys. J. Int., $157,775-795$.

Al-Husseini M I (2000) Origin of the Arabian plate structures: Amar collision and Najd rift, GeoArabia, 5(4), 527-542

Astiz, L (1997). How to Estimate Power Spectral Density of Seismic Noise for FDSN Broadband Digital Stations", USGS Open-File Report 93-322, 95 pp.

Badri, M. (1991). Crustal structure of central Saudi Arabia determined from seismic refraction profiling, Tectonophysics, 185, 357-374.

Benoit, M., A. Nyblade, J. VanDecar and H. Gurrola (2003). Upper mantle P wave velocity structure and transition zone thickness beneath the Arabian Shield, Geophys. Res. Lett., 80, doi:10.1029/2002GL016436.

Debayle, E., J. Leveque, and M. Cara (2001). Seismic evidence for a deeply rooted low- velocity anomaly in the upper mantle beneath the northeastern Afro/Arabian continent, Earth Planet. Sci. Lett., 193, 423-436.

Gettings, M., H. Blank, W. Mooney and J. Healey (1986). Crustal structure of southwestern Saudi Arabia, J. Geophys. Res., 91, 6491- 6512. 
Looseveld R J H, Bell A, Terken J J M (1996) The tectonic evolution of interior Oman, GeoArabia, 1 (1), 28-51

Mellors, R. (1998). Preliminary noise survey and data report of Saudi Arabian data, Lawrence Livermore National Laboratory, Technical Report, UCRL-ID-128949.

Mellors. R., F. Vernon (1999). Analysis of data from the broadband Saudi Arabian deployment, final report to Lawrence Livermore National Laboratory, 29 pp.

Mokhtar, T., C. Ammon, H. Ghalib, and R. Herrmann (1997). Lithospheric structure beneath Arabia, EOS, 78, F499.

Mooney, W., M. Gettings, H. Blank and J. Healy (1985). Saudi Arabian seismic refraction profile: a traveltime interpretation of crustal and upper mantle structure, Tectonophysics, 111, 173-246.

Pasyanos, M. P., W. R. Walter and E. M. Matzel (2009). A simultaneous multiphase approach to determine P-wave and S-wave attenuation of the crust and upper mantle, Bull. Seismo. Soc. Amer., 99, 3314-3325.

Park, Y., A. Nyblade, A. Rodgers and A. M Al-Amri (2007). Upper mantle structure beneath the Arabian Peninsula from regional body-wave tomography: Implications for the origin of Cenozoic uplift and volcanism in the Arabian Shield, Geochemistry, Geophysics, Geosystems, 8, doi:10.1029/2006GC001566.

Peterson, J. (1993). Observations and Modeling of Seismic Background Noise, U.S. Geological Survey Open - File Report 93-322.Albuquerque, New Mexico, 94 pp. 
Powers R W, Ramirez L F, Redmond C D, and Elberg E L (1966). Geology of the Arabian Peninsula, Sedimentary geology of Saudi Arabia: U. S. Geological Survey professional paper 560-D D1-D147

Rodgers, A., W. Walter, R. Mellors, A. M. S. Al-Amri and Y. S. Zhang (1999). Lithospheric structure of the Arabian Shield and Platform from complete regional waveform modeling and surface wave group velocities, Geophys. J. Int., 138, 871-878.

Sandvol, E., D. Seber, M. Barazangi, F. Vernon, R. Mellors, and A. Al-Amri (1998), Lithospheric seismic velocity discontinuities beneath the Arabian Shield, Geophys. Res. Lett., $25,2873-2876$.

Tkalčiç, H., M. Pasyanos, A. Rodgers, R. Gok and A. Al-Amri (2006). A multi-step approach for joint modeling of surface wave dispersion and teleseismic receiver functions: Implications for lithospheric structure of the Arabian Peninsula. J. Geophys. Res., 111, B113111, doi:10.1029/2005JB004130.

Vernon, F. and J. Berger (1997). Broadband seismic characterization of the Arabian Shield, Final Scientific Technical Report, Department of Energy Contract No. F 19628-95-K-0015, 36 pp. 


\section{Figure Captions}

Figure 1 (a) Location map of the Arabian Plate showing major tectonic elements of the Arabian Shield and Platform (Al-Husseini,2000) and the position of the Ar Rayn seismic array (triangle). Earthquakes greater than magnitude 5 for the period 2000-2010 and volcanic centers are indicated by black circles and white diamonds, respectively. (b) The array geometry, which has a broadband sensor (STS-2) at its center (triangle with circle), surrounded by two rings of short-period sensors (triangles).

Figure 2 Station sites were chosen for Precambrian bedrock contact. Site preparation included excavation to undisturbed bedrock with heavy equipment.

Figure 3 Typical vault installation of a short period three-component instrument. The concrete pier was poured directly on bedrock.

Figure 4 Average ambient noise levels for the three components of the central broadband element AR00 (vertical, north and east as solid, dashed, dashed-dotted lines, respectively). The noise power spectral densities are expressed in acceleration power relative to $1 \mathrm{~m} * * 2 / \mathrm{s} * * 4 / \mathrm{Hz}$ in decibels (dB). Reported low and high noise models from Peterson (1993) are shown as gray lines.

Figure 5 FK spectrum, computed between 1 and $3 \mathrm{~Hz}$, of the initial $\mathrm{P}$ phase for an earthquake in the vicinity of Greece that occurred on January 22, 2010. The cut P phase waveforms are shown at left, and the FK spectrum to the right. Coherence of this near phase is high as is expected of a teleseismic observation; the measured backazimuth and phase velocity are used to align the waveforms for a coherence measurement. 
Figure 6 Coherence of the teleseismic P phase at the array is high, demonstrating uniformity of installation and instrumentation. At top, the $\mathrm{P}$ waves of the teleseism from Greece are superimposed to show the domain of calculation of signal correlation. At the bottom, the 21 correlation coefficients between unique pairs of sensors are shown plotted as a function of sensor separation. The P phase is relatively narrowband, with most of its energy just above $1 \mathrm{~Hz}$. Therefore coherence is expected to be high, but nonetheless indicates proper installation of the instrumentation.

Figure 7 This small central Arabian event about 260 kilometers from the array has a low SNR that makes observation of the $\mathrm{P}$ phases difficult. A window around the $\mathrm{Lg}$ phase from 90 to 100 seconds allows backazimuth estimation with an FK spectrum.

Figure 8 An FK spectrum of the Lg phase of the small central Arabian event provides a usable backazimuth. The measured phase velocity is consistent with Lg propagation.

Figure 9 Beamforming greatly enhances our ability to interpret the P phase of this small central Arabian event. The top trace is the waveform from a single vertical sensor of the array filtered into the 0.8 to $3 \mathrm{~Hz}$ band. The second trace is the conventional beam made with the vertical elements of the array, using the Lg backazimuth (29.5 degrees) and an assumed Pn phase velocity of $8 \mathrm{~km} / \mathrm{sec}$. The third trace is the beam formed from all seven three-component traces, assuming polarization consistent with Pn (P medium velocity of $5 \mathrm{~km} / \mathrm{sec}$; incidence angle of 39 degrees).

Figure 10 Result of beamforming for the initial P phases of a magnitude 3.9 event at the Harrat Lunnayir volcanic field approximately 790 kilometers from the array. The top trace is a single short-period vertical channel filtered into the $1-4 \mathrm{~Hz}$ band. The signal is dominated by $\mathrm{Lg}$, 
but a small Pn arrival is visible around 190 seconds. Below are detailed traces referenced to the boxed interval of the top trace. These traces display again the filtered single trace, a vertical beam on the Pn velocity and backazimuth and a three-component beam. The beams show the Pn arrival more clearly and the three-component beam also provides a clearer view of the Pg arrival. 

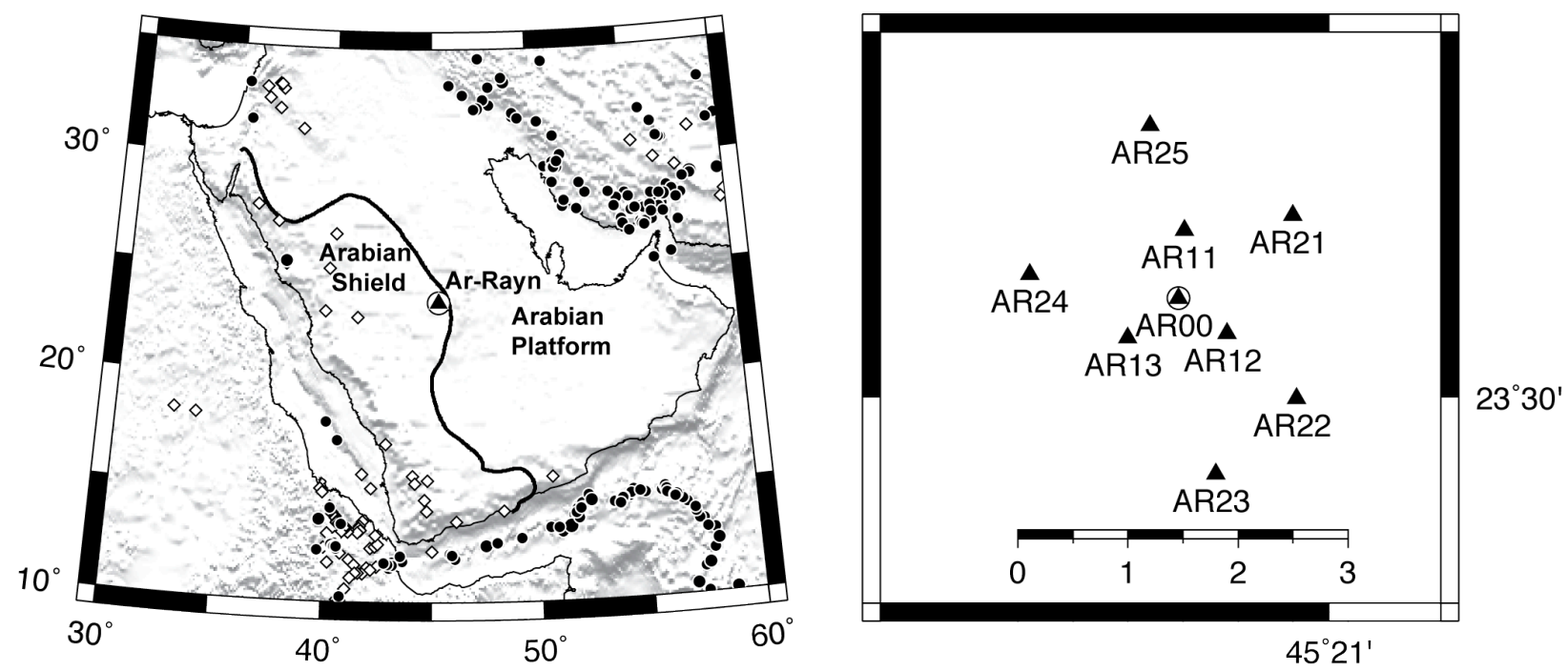

Figure 1 


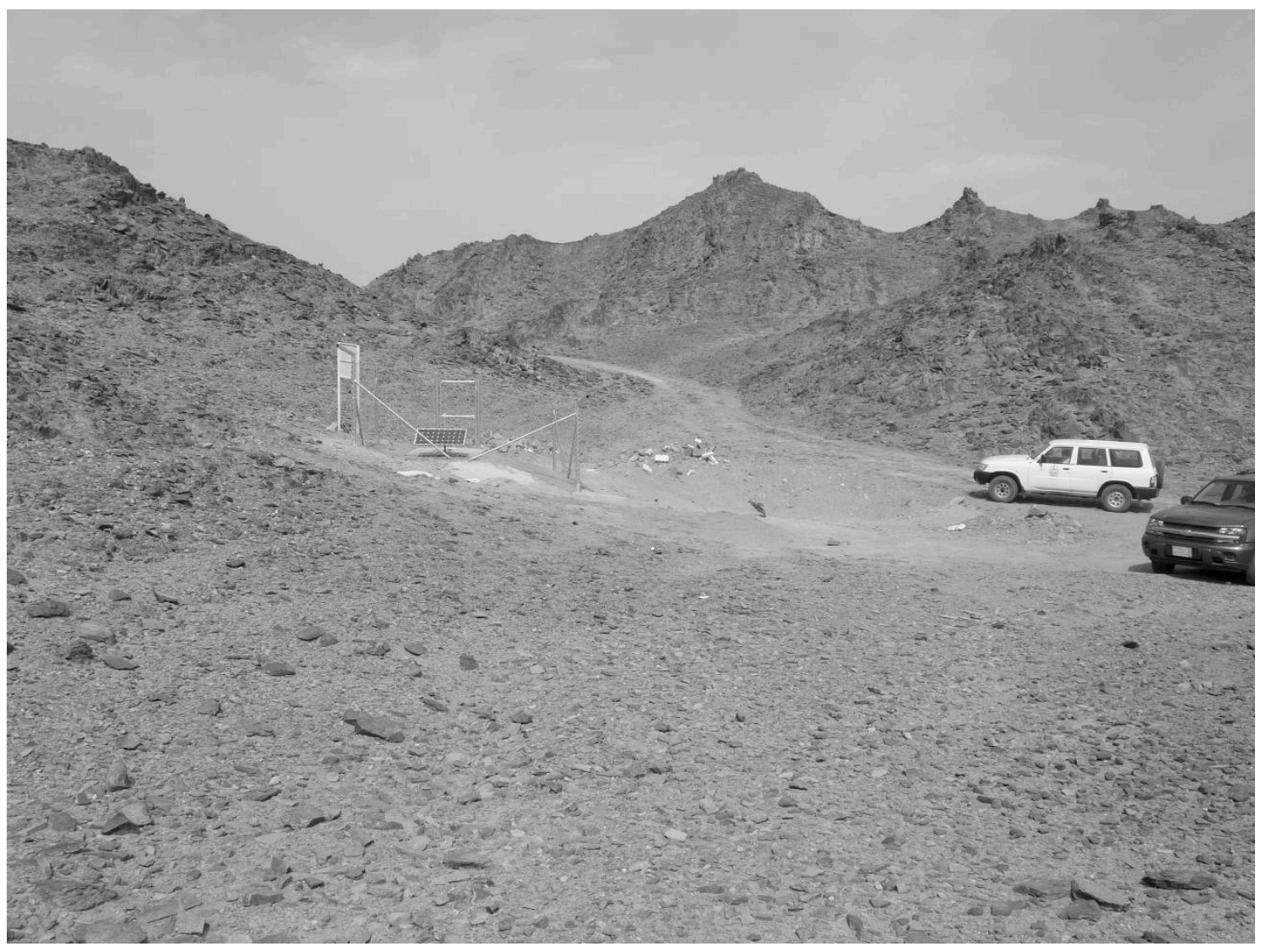

Figure 2 


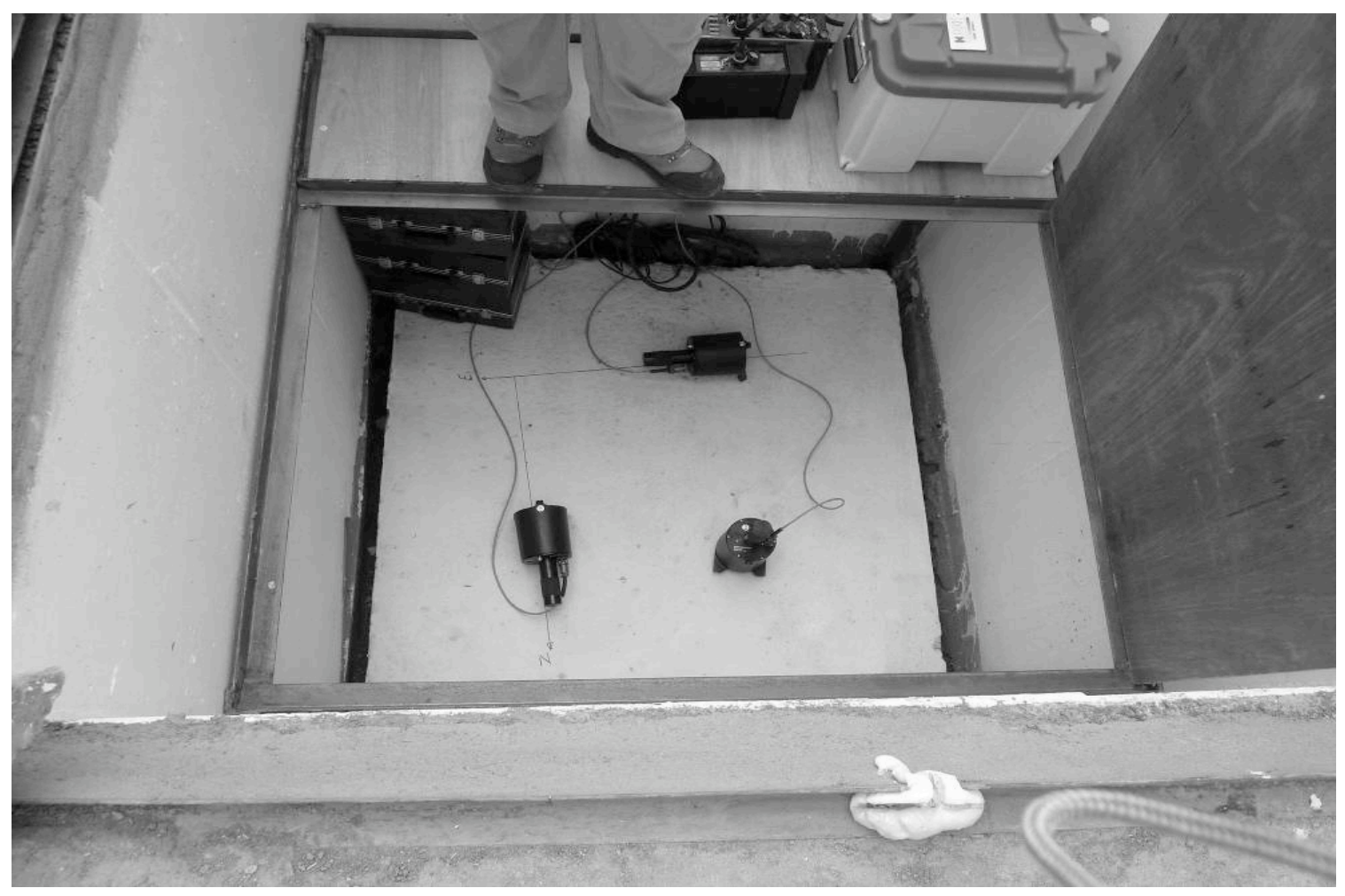

Figure 3 


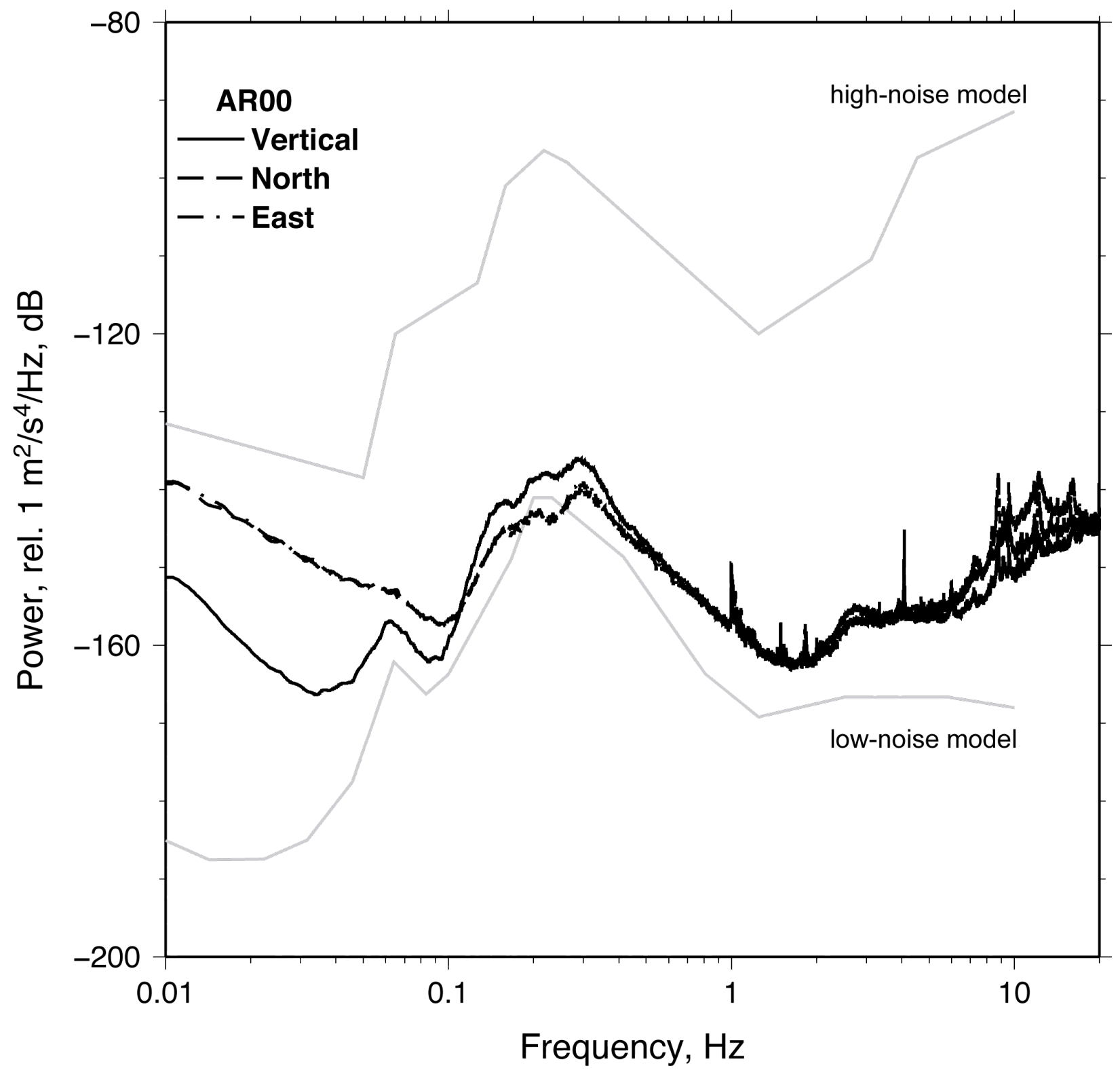

Figure 4 


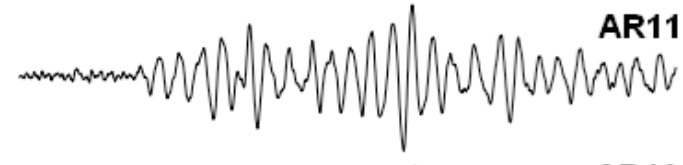

smenamanum AR12

ARmonis

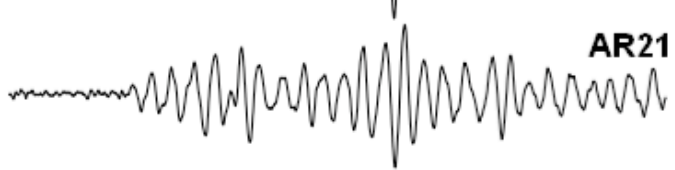

mor22

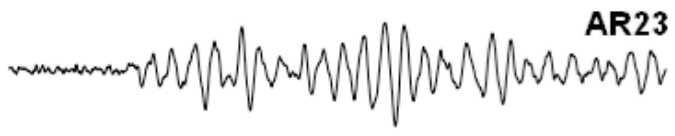

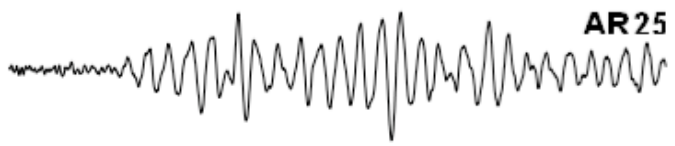

\begin{tabular}{|c|c|c|c|c|c|c|}
\hline 1 & $T$ & $T$ & $T$ & $T$ & $T$ & \\
\hline 0 & 5 & 10 & 15 & 20 & 25 & 30 \\
\hline
\end{tabular}

Backazimuth: -63.435 Velocity: 10.164

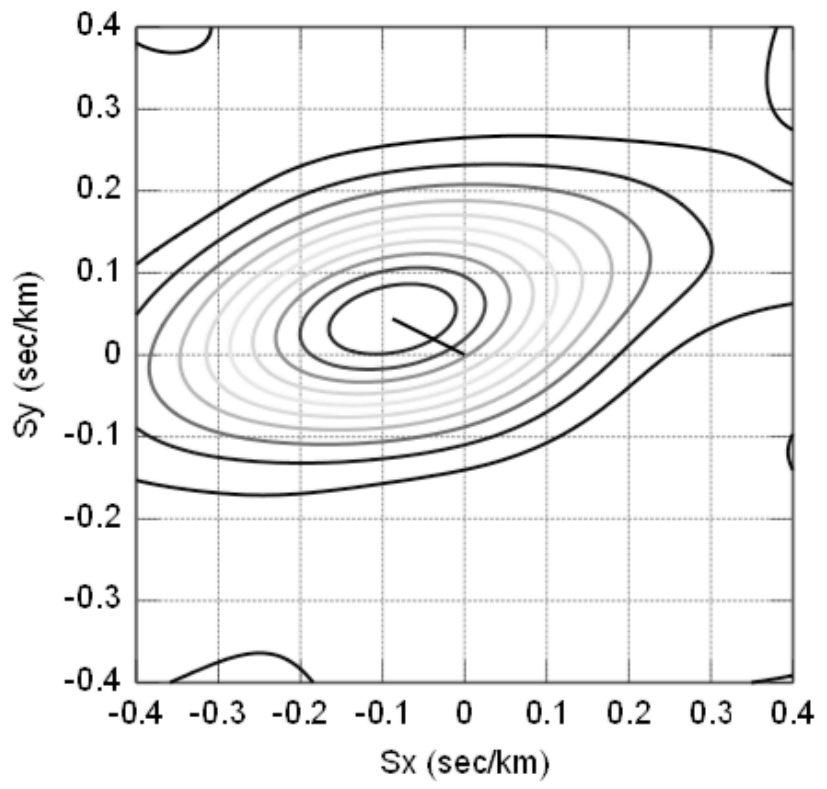

Figure 5 

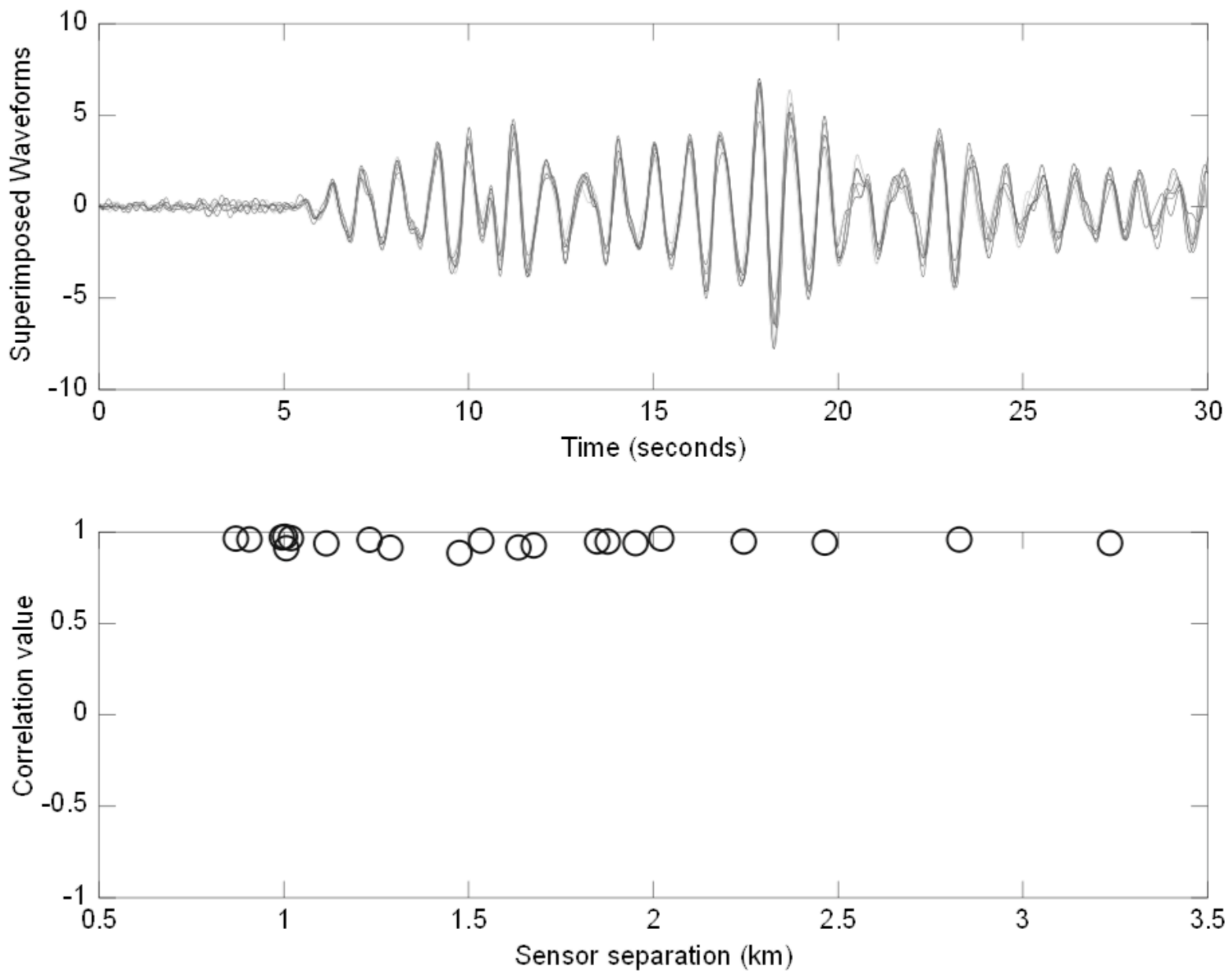

Figure 6 


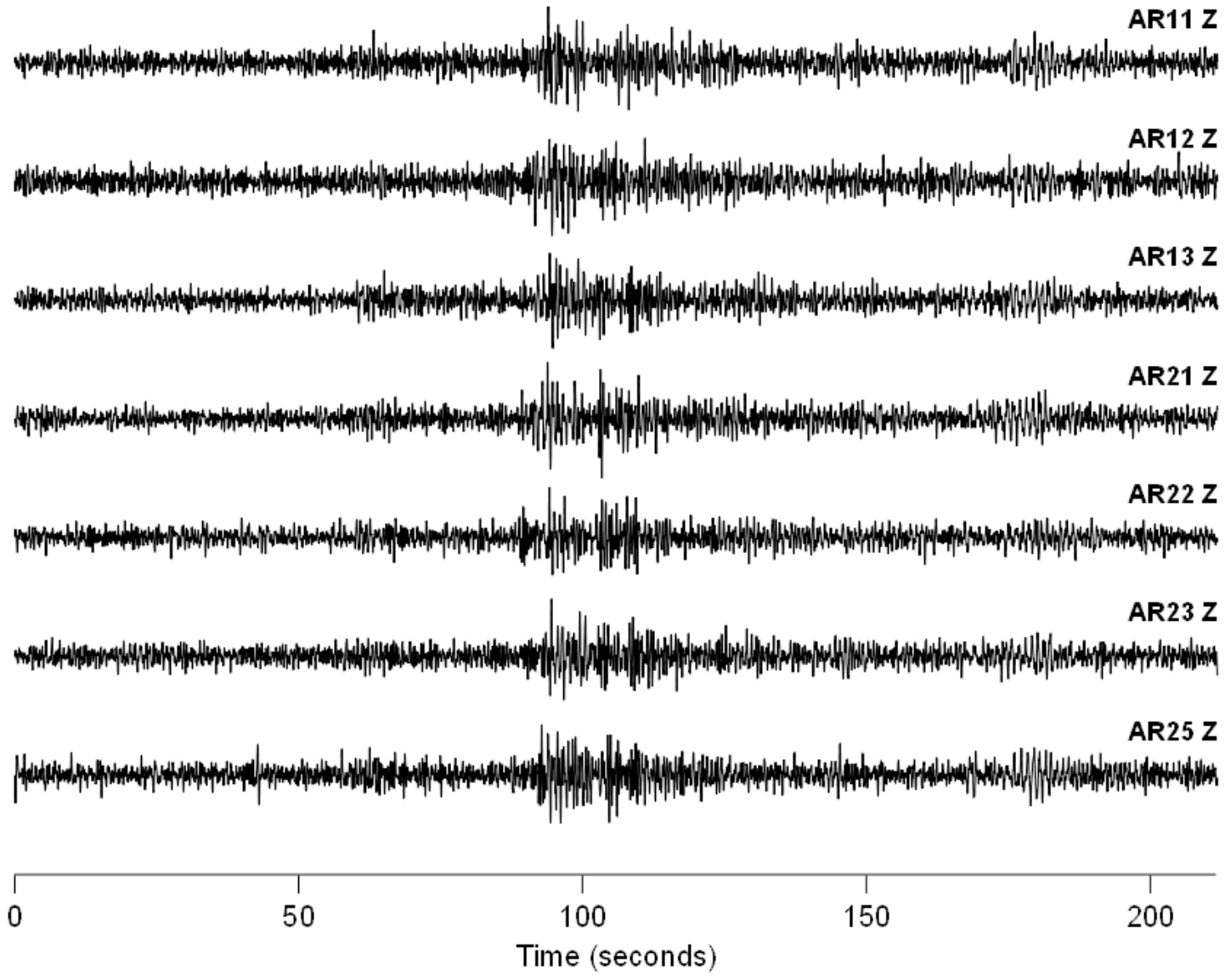

Figure 7 


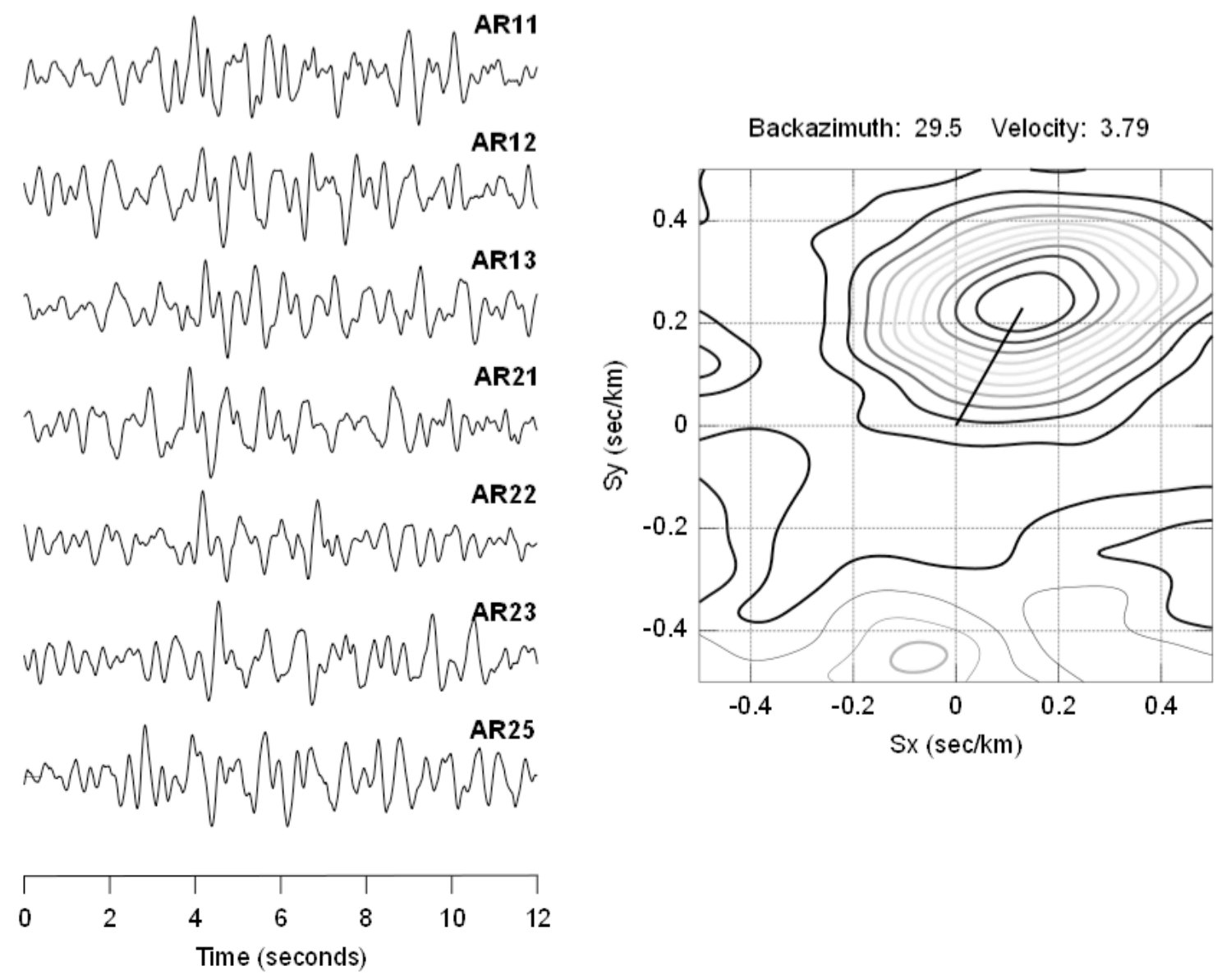

Figure 8 

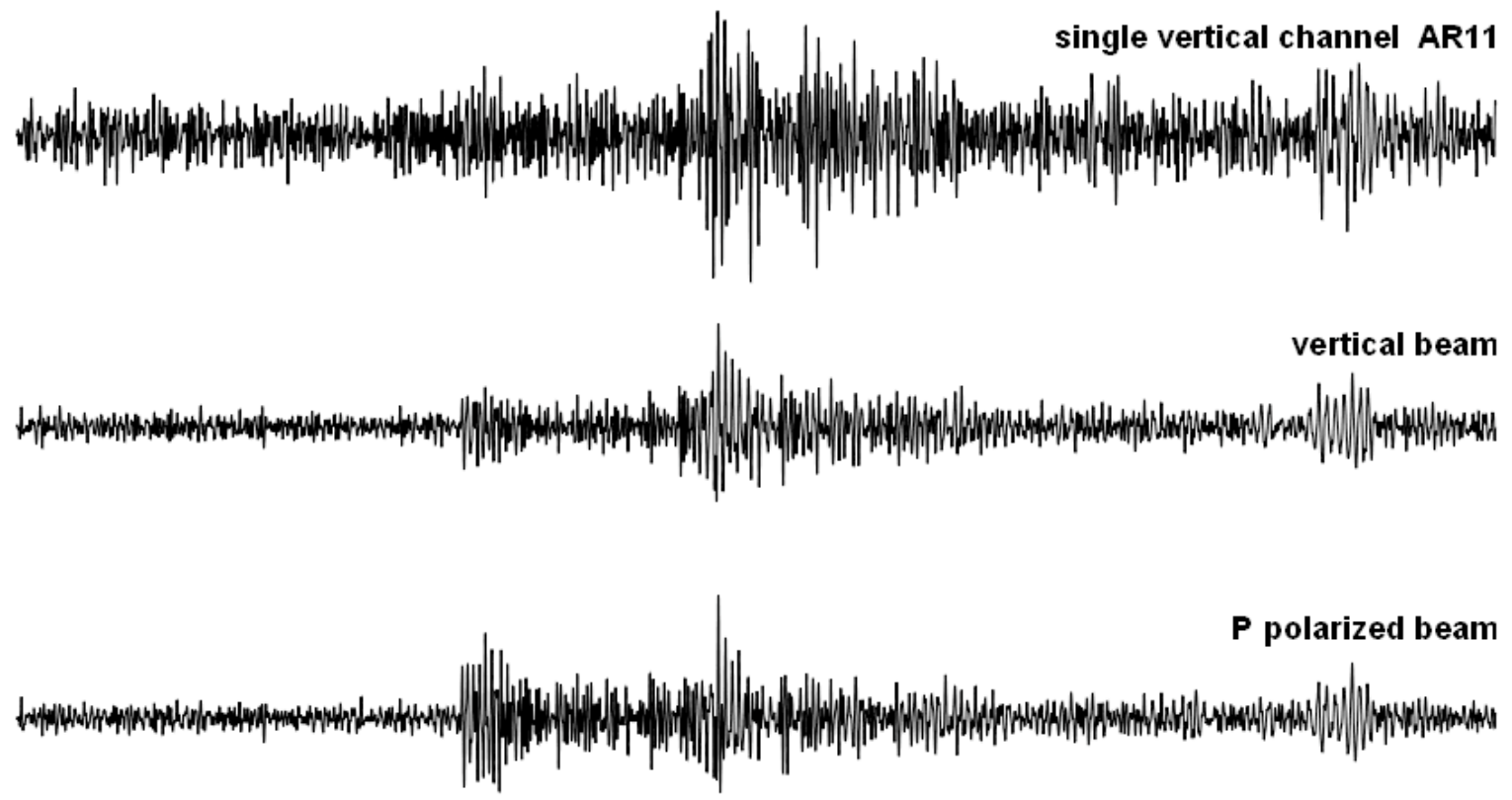

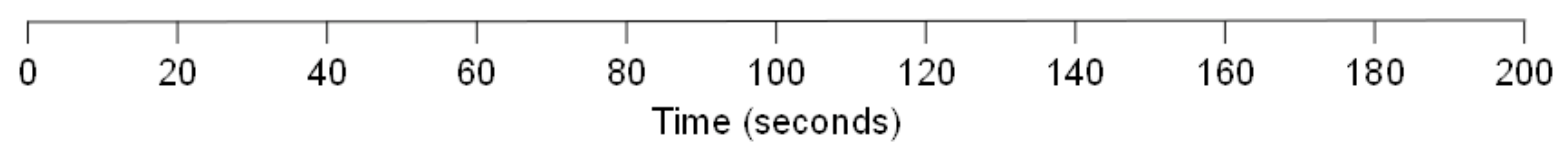

Figure 9 

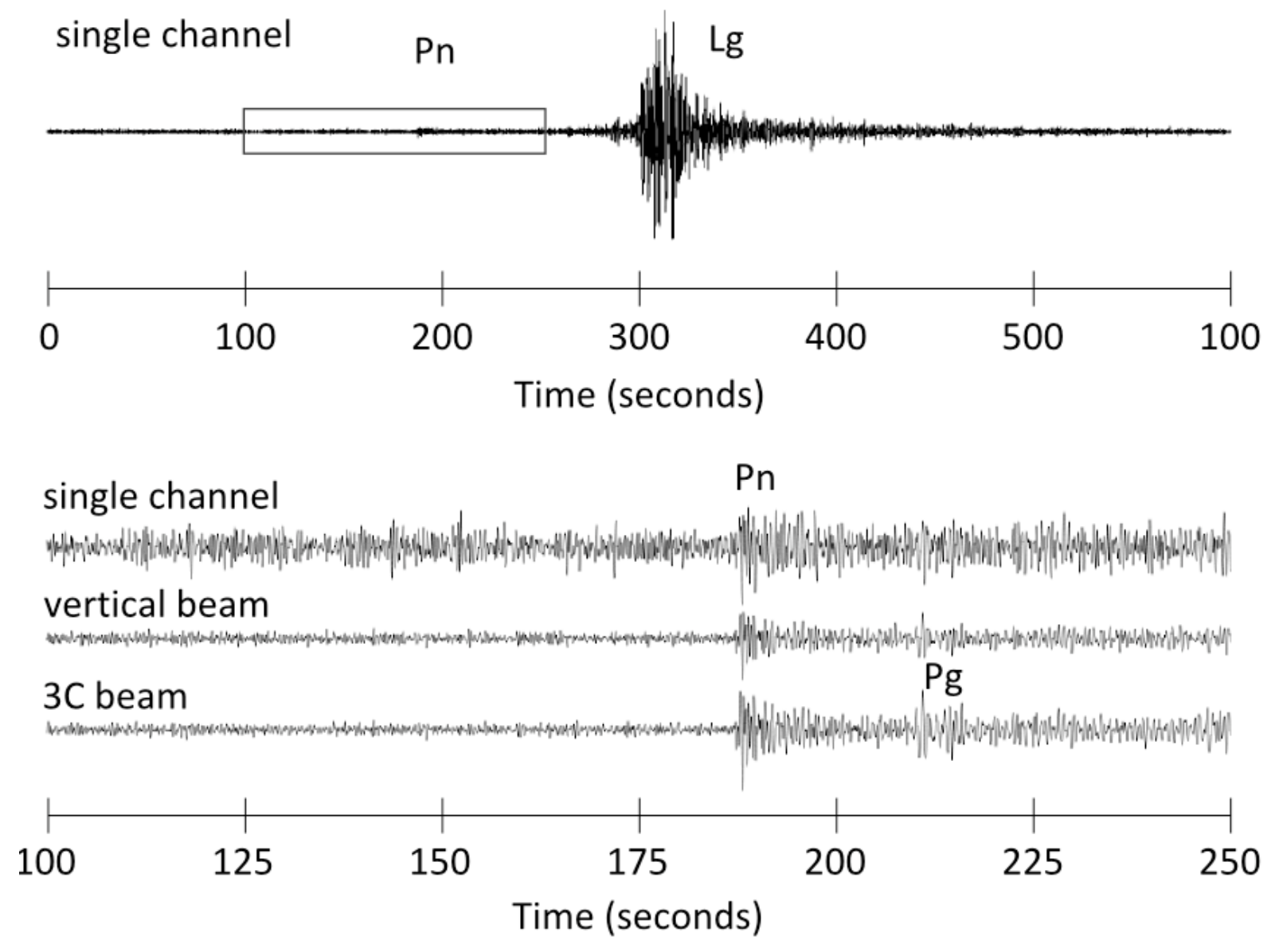

Figure 10 